\title{
Anionic Copolymerizations of trans-Stilbene with Butadiene, Isoprene, and 2,3-Dimethylbutadiene
}

\author{
Heimei Yuki, Yoshio OKamoto, Katsuya Tsubota, and Koichi KosaI \\ Department of Chemistry, Faculty of Engineering Science, Osaka University, Toyonaka, Osaka, Japan.
}

(Received August 28, 1969)

\begin{abstract}
Anionic copolymerizations of trans-stilbene $\left(\mathrm{M}_{2}\right)$ with butadiene $\left(\mathrm{M}_{1}\right)$, isoprene $\left(\mathrm{M}_{1}\right)$, and 2,3-dimethylbutadiene $\left(\mathrm{M}_{1}\right)$ were studied in tetrahydrofuran (THF) at $0^{\circ} \mathrm{C}$ and in benzene at $40^{\circ} \mathrm{C}$ by means of $n$-butyllithium $(n-\mathrm{BuLi})$ as an initiator. All the copolymerizations in THF gave alternating copolymers, and the rate of the consumption of $\mathrm{M}_{1}$ decreased as follows: butadiene $>$ isoprene $>2,3$-dimethylbutadiene. The copolymerizations with isoprene and 2,3-dimethylbutadiene in THF spontaneously stopped, and the unchanged $\mathrm{M}_{1}$ monomers remained when the concentration of $n-\mathrm{BuLi}$ was low, where the final yields were lower in the copolymerization with 2,3-dimethylbutadiene with the same concentration of $n$-BuLi. The final yields increased with an increase in $n$-BuLi and decreased with increasing $\left[\mathrm{M}_{2}\right]_{0} /\left[\mathrm{M}_{1}\right]_{0}$ ratio. The copolymerization with butadiene was completed without the remaining $\mathrm{M}_{1}$ monomer. In all cases the electronic spectra of the reaction mixtures in THF showed no peak near $540 \mathrm{~m} \mu$ in the initial stage of the reactions, but a new peak appeared near $540 \mathrm{~m} \mu$ in time. The order of the optical densities of the peak after a prolonged time was 2,3-dimethylbutadiene $>$ isoprene $>$ butadiene. The microstructures of the dienes in the homopolymers and alternating copolymers which were polymerized in THF were determined by NMR spectroscopy. The alternating copolymers had more 1,4-structure than the corresponding homopolymers, and the 1,4-content in the formers decreased in the following order: 2,3-dimethylbutadiene $>$ isoprene $>$ butadiene. The dienes, however, were completely consumed in the copolymerizations in benzene. In the copolymerizations with butadiene and isoprene, little transstilbene was incorporated into the copolymers, but a considerable amount of trans-stilbene was copolymerized with 2,3-dimethylbutadiene.

KEY WORDS Anionic Copolymerization / trans-Stilbene / Butadiene / Isoprene / 2,3-Dimethylbutadiene / THF / Benzene / $n$-BuLi / Alternating Copolymer /
\end{abstract}

Anionic copolymerizations of 1,1-diphenylethylene with styrene ${ }^{1}$ or conjugated dienes ${ }^{2-5}$ proceeded without chain transfer and termination reactions to give alternating copolymers in THF. The copolymerization of trans-stilbene and styrene in THF also gave an alternating copolymer under appropriate reaction conditions, but a chaintransfer occurred, ${ }^{6}$ the mechanism of which has been clarified recently. ${ }^{7}$

In this work, the copolymerizations of transstilbene with butadiene, isoprene, and 2,3-dimethyllbutadiene are investigated in THF and benzene by means of $n$-BuLi.

\section{EXPERIMENTAL}

\section{Materials}

trans-Stilbene
The monomer synthesized from benzoin ${ }^{8}$ was recrystallized three times from methanol and twice from $n$-hexane. $\mathrm{Mp} 124^{\circ} \mathrm{C}$.

\section{Butadiene}

Butadiene (Phillips, polymerization grade) dried over Molecular Sieves was mixed with solventfree $n$-BuLi before use. The monomer was then distilled in vacuo to a reaction vessel.

\section{Isoprene}

The monomer (Phillips, polymerization grade) dried over Molecular Sieves was transferred on to lithium aluminum hydride, from where it was redistilled under high vacuum before use.

\section{2,3-Dimethylbutadiene}

This was synthesized by dehydration of pinacol. ${ }^{9}$ The monomer, purified by fractional distillation, was stored over lithium aluminum hydride. Before 
use, it was distilled on a vacuum line.

THF

The solvent was first refluxed over sodium and then over lithium aluminum hydride. This was then distilled on to benzophenone and $\mathrm{Na}-\mathrm{K}$ alloy to form a blue solution, from which the solvent was distilled on the vacuum system just before use.

\section{Benzene}

$n$-BuLi in benzene was added to the solvent purified in the usual manner and then the solvent was distilled in vacuo.

\section{$n-B u L i$}

According to the method of Ziegler, ${ }^{10} n$-BuLi was prepared from $n$-butyl chloride and metallic lithium in $n$-heptane.

\section{n-Butyl Alcohol}

A small amount of $\mathrm{Na}-\mathrm{K}$ alloy was added to the alcohol (spectro grade) under dry nitrogen. The alcohol containing butoxides was then distilled in vacuo to a glass ampoule to prepare a standard $n$-butyl alcohol solution in $n$-heptane. The solution was used for the colorimetric titration of a colored carbanion solution.

\section{Polymerization}

Under the atmosphere of dry nitrogen transstilbene was placed in a glass ampoule which had been dried by heating with a hand torch in vacuo, and then the monomer was dried under high vacuum. To the ampoule, a comonomer solution prepared on the vacuum system was added with a hypodermic syringe. $n$-BuLi was added dropwise until a red color due to a stilbenyl anion was stable; usually $c a$. 0.04-0.06 mmol of invalid $n$-BuLi was required for $15 \mathrm{~m} l$ solution. Then additional $n$-BuLi was added as an effective initiator. In the case of the reaction in benzene, a yellow color of the anion appeared very slowly. Therefore, the same amount of the invalid $n$-BuLi in THF was estimated. The polymerization was terminated by the addition of a standard $n$-butyl alcohol solution in order to titrate the concentration of the carbanion present in the system. The reaction mixture was poured into methanol. The polymer precipitated in methanol was filtrated, washed with methanol, and weighed. On the other hand, the mother liquor and the washings of the polymer precipitation were combined and evapo- rated under reduced pressure to recover unchanged trans-stilbene.

\section{NMR Spectrum}

The spectrum of the polymer was taken on a JNM-4H-100 Spectrometer (Japan Electron Optics Laboratory Co., Ltd.) at $100 \mathrm{MHz}$ in carbon tetrachloride at $60^{\circ} \mathrm{C}$ by using tetramethylsilane as an internal standard.

\section{UV Spectrum}

The UV spectrum of the reaction solution was measured with a Hitachi 124 Spectrophotometer. The sample solution was prepared according to the procedure in the "Polymerization" described above.

\section{Viscosity}

The solution viscosity of the polymer was measured in toluene at $30.0^{\circ} \mathrm{C}$.

\section{RESULTS}

\section{Polymerization in THF}

The copolymerizations of trans-stilbene $\left(\mathrm{M}_{2}\right)$ with butadiene $\left(\mathrm{M}_{1}\right)$, isoprene $\left(\mathrm{M}_{1}\right)$, and 2,3dimethylbutadiene $\left(\mathrm{M}_{1}\right)$ were investigated with $n$-BuLi at $0^{\circ} \mathrm{C}$. The results are shown in Figure 1.

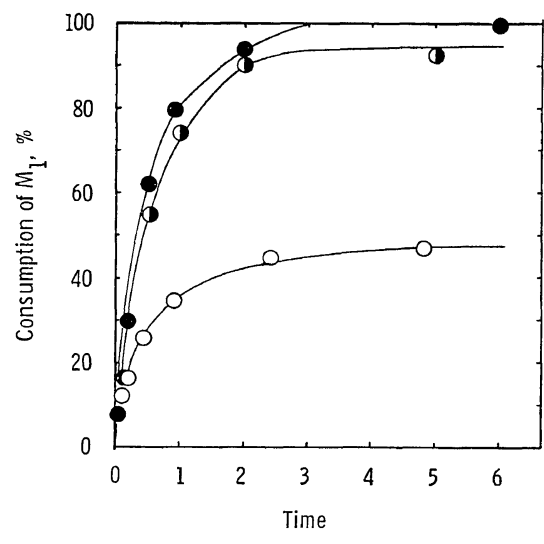

(Bd: $\times 10 \mathrm{~min}, \mathrm{Isp}: \mathrm{hr}, \mathrm{DMB}: \times 10 \mathrm{hr}$ )

Figure 1. Anionic copolymerizations of trans-stilbene $\left(\mathrm{M}_{2}\right)$ and dienes $\left(\mathrm{M}_{1}\right)$ by $n$-BuLi in THF; time vs. polymer yield.

: $[\mathrm{Bd}]_{0}, 5.42 \mathrm{mmol},\left[\mathrm{M}_{2}\right]_{0}, 5.55 \mathrm{mmol},[n-\mathrm{BuLi}]$, $0.047 \mathrm{mmol}$.

: [Isp]o, $5.60 \mathrm{mmol},\left[\mathrm{M}_{2}\right]_{0}, 5.30 \mathrm{mmol},[n$-BuLi], $0.056 \mathrm{mmol}$.

$\bigcirc:[\mathrm{DMB}]_{0}, 3.96 \mathrm{mmol},\left[\mathrm{M}_{2}\right]_{0}, 4.44 \mathrm{mmol},[n-\mathrm{BuLi}]$, $0.040 \mathrm{mmol}$.

THF $15 \mathrm{ml}$, Temp. $0^{\circ} \mathrm{C}$. 
Since these copolymerizations gave alternating copolymers as will be stated later, the consumptions of the dienes were used as a measure of the polymer yield. The rates of the consumptions of the dienes decreased in the following order: butadienei $>$ isoprene $>2,3$-dimethylbutadiene. In the copolymerizations using isoprene and 2,3dimethylbutadiene as comonomers, the reactions were spontaneously terminated, and the unchanged $\mathbf{M}_{1}$ monomers remained. All the copolymers obtained were powder.

It was rather difficult to carry out all the polymerizations under the same reaction conditions keeping the quantity of invalid $n$-BuLi constant (see Experimental section). Therefore, the authors examined whether the final yield of polymer was affected or not by the extent of dryness of the reaction system which should relate to the invalid $n$-BuLi. The results are shown in Table I. It was found that the final yield was independent of the quantity of the invalid
$n$-BuLi.

The copolymer composition was calculated from the weights of the monomers, the copolymers, and the recovered $\mathbf{M}_{2}$ monomer, as is shown in Table II. The copolymer compositions were approximately unity regardless of the polymer yield, and the values were equal to those determined by NMR spectroscopy within experimental errors. This means that all the copolymers were essentially alternating because the homopolymerizability of trans-stilbene is very small.

The relationship between monomer composition and polymer yield after a prolonged reaction time was investigated in the copolymerizations with 2,3-dimethylbutadiene and butadiene at constant concentrations of the $\mathrm{M}_{1}$ monomers. The results are shown in Figure 2 and Table III. The consumption of 2,3-dimethylbutadiene decreased with an increase in the $\left[\mathrm{M}_{2}\right]_{0} /\left[\mathrm{M}_{1}\right]_{0}$ ratio. On the other hand, butadiene was completely

Table I. Anionic copolymerization of trans-stilbene $\left(\mathrm{M}_{2}\right)$ and dienes $\left(\mathrm{M}_{1}\right)$ by $n$-BuLi in THFa

\begin{tabular}{ccccccc}
\hline $\mathrm{M}_{1}$ & $\begin{array}{c}\text { Invalid } \\
n \text {-BuLi }(\mathrm{mmol})^{\mathrm{b}}\end{array}$ & $\begin{array}{c}\text { Valid } n \text {-BuLic } \\
(\mathrm{mmol})\end{array}$ & $\begin{array}{c}{\left[\mathrm{M}_{1}\right]_{0}} \\
(\mathrm{mmol})\end{array}$ & $\begin{array}{c}\text { Time } \\
(\mathrm{hr})\end{array}$ & $\begin{array}{c}\text { Polymer } \\
(\mathrm{g})\end{array}$ & $\begin{array}{c}\text { Yield } \\
(\%)^{\mathrm{d}}\end{array}$ \\
\hline Isoprene & 0.058 & 0.058 & 4.96 & 40 & 1.049 & 87.8 \\
Isoprene & 0.117 & 0.058 & 4.96 & 40 & 1.051 & 88.0 \\
2,3-DMB & 0.057 & 0.046 & 4.44 & 84 & 0.977 & 84.1 \\
2,3-DMB & 0.092 & 0.042 & 4.44 & 84 & 0.943 & 81.3 \\
\hline
\end{tabular}

a $\left[\mathrm{M}_{1}\right]_{0} /\left[\mathrm{M}_{2}\right]_{0}, 1.0, \mathrm{THF}, 15 \mathrm{ml}, \mathrm{Temp} ., 0^{\circ} \mathrm{C}$.

b $n$-BuLi used until a red color due to stilbenyl anion was stable.

c $n$-BuLi used for the propagation reaction.

d Consumption of $\mathrm{M}_{1}$.

Table II. Anionic copolymerizations of trans-stilbene $\left(\mathrm{M}_{2}\right)$ and dienes $\left(\mathrm{M}_{1}\right)$ by $n$-BuLi in THFa (Copolymer composition)

\begin{tabular}{|c|c|c|c|c|c|c|c|}
\hline \multirow{2}{*}{$\mathrm{M}_{1}^{\mathrm{b}}$} & \multirow{2}{*}{$\begin{array}{l}M_{1} \\
(g)\end{array}$} & \multirow{2}{*}{$\begin{array}{l}\mathrm{M}_{2} \\
(\mathrm{~g})\end{array}$} & \multirow{2}{*}{$\begin{array}{c}{\left[\mathrm{M}_{1}\right]_{0} /\left[\mathrm{M}_{2}\right]_{0}} \\
(\mathrm{~mol} / \mathrm{mol})\end{array}$} & \multirow{2}{*}{$\begin{array}{l}\text { Polymer } \\
\text { (g) }\end{array}$} & \multirow{2}{*}{$\begin{array}{c}\text { Recovered } \\
\mathrm{M}_{2}(\mathrm{~g})^{\mathrm{c}}\end{array}$} & \multicolumn{2}{|c|}{ Copolymer composition } \\
\hline & & & & & & $\mathrm{m}_{1}(\mathrm{mmol})$ & $\mathrm{m}_{2}(\mathrm{mmol})$ \\
\hline $\mathrm{Bd}$ & 0.293 & 1.000 & 0.977 & 0.200 & 0.848 & 0.89 & 0.85 \\
\hline $\mathrm{Bd}$ & 0.293 & 1.000 & 0.977 & 0.791 & 0.378 & 3.14 & 3.45 \\
\hline $\mathrm{Bd}$ & 0.293 & 1.000 & 0.977 & 1.198 & 0.075 & 5.05 & 5.14 \\
\hline Isp & 0.375 & 0.935 & 1.057 & 0.723 & 0.410 & 2.91 & 2.91 \\
\hline Isp & 0.375 & 0.935 & 1.057 & 0.964 & 0.235 & 3.89 & 3.89 \\
\hline Isp & 0.375 & 0.935 & 1.057 & 1.247 & 0.032 & 5.06 & 5.03 \\
\hline DMB & 0.325 & 0.798 & 0.893 & 0.164 & 0.689 & 0.73 & 0.61 \\
\hline DMB & 0.325 & 0.798 & 0.893 & 0.358 & 0.534 & 1.15 & 1.46 \\
\hline DMB & 0.325 & 0.798 & 0.893 & 0.494 & 0.453 & 1.82 & 1.91 \\
\hline
\end{tabular}

a THF, $15 \mathrm{ml}$, Temp., $0^{\circ} \mathrm{C}$.

b Bd: Butadiene, Isp: Isoprene, DMB: 2,3-Dimethylbutadiene.

c Contained ca. $7 \mathrm{mg}$ of lithium compounds. 
Table III. Anionic copolymerization of butadiene $\left(\mathrm{M}_{1}\right)$ and trans-stilbene $\left(\mathrm{M}_{2}\right)$ by $n$-BuLi in THF

(Relationship between monomer composition and polymer yield)

\begin{tabular}{cccccc}
\hline $\begin{array}{c}\mathrm{M}_{2} \\
(\mathrm{~g})\end{array}$ & $\begin{array}{c}{\left[\mathrm{M}_{1}\right]_{0} /\left[\mathrm{M}_{2}\right]_{0}} \\
(\mathrm{~mol} / \mathrm{mol})\end{array}$ & $\begin{array}{c}\text { Polymer } \\
(\mathrm{g})\end{array}$ & $\begin{array}{c}\text { Recovered } \\
\mathrm{M}_{2}(\mathrm{~g})\end{array}$ & \multicolumn{2}{c}{ Copolymer composition } \\
\cline { 5 - 6 } & 1.08 & 1.098 & 0.020 & 4.58 & $\mathrm{~m}_{1}(\mathrm{mmol})$ \\
\hline 0.850 & 1.08 & 1.241 & 0.035 & 5.10 & $\mathrm{~m}_{2}(\mathrm{mmol})$ \\
1.000 & 0.92 & 1.312 & 0.162 & 5.10 & 5.36 \\
1.200 & 0.76 & 1.354 & 0.266 & 5.00 & 6.02 \\
1.350 & 0.68 & 1.410 & 0.463 & 5.05 & 6.44 \\
1.600 & 0.57 & &
\end{tabular}

a $\mathrm{M}_{1}, 0.276 \mathrm{~g}(5.10 \mathrm{mmol})$, THF, $15 \mathrm{ml}, n$-BuLi, $0.04 \mathrm{mmol}$, Temp., $0^{\circ} \mathrm{C}$, Time, $24 \mathrm{hr}$.

consumed regardless of the monomer composition, where the copolymer composition, $\left[\mathrm{m}_{1}\right] /$ $\left[\mathrm{m}_{2}\right]$, slightly decreased as the $\left[\mathrm{M}_{1}\right]_{0} /\left[\mathrm{M}_{2}\right]_{0}$ decreased. These results suggest that trans-stilbene related to a termination reaction, and that at a high concentration of trans-stilbene, stilbenestilbene units must have been formed in the copolymer but their sequence length would be two at most. ${ }^{7}$

The effect of initiator concentration on the polymer yield was studied in the copolymerizations with isoprene and 2,3-dimethylbutadiene. Figure 3 shows the results, in which the reaction time was so long that both the reactions were completed. At low concentration of $n$-BuLi the dienes remained unchanged, even after the completion of the reaction, but the polymer yield was increased by increasing the concentration of $n$ BuLi. The solution viscosities of the copolymers with isoprene and 2,3-dimethylbutadiene obtained in the above copolymerizations were almost constant regardless of the initiator concentration: i.e., $0.14-0.16$ and $0.10 \mathrm{~d} l / \mathrm{g}$, respectively.

The colors of all reaction mixtures were red in the initial stage, but they gradually turned purple; especially in the copolymerization with 2,3-dimethylbutadiene the change was remarkable. The electronic spectra of the reaction systems $\left(\left[\mathrm{M}_{1}\right]_{0} /\left[\mathrm{M}_{2}\right]_{0} \simeq 1\right)$ were measured under the reaction conditions similar to those in the copolymerizations. The mixtures showed no peak near $540 \mathrm{~m} \mu$ in the initial stage of the reaction, but a new peak appeared near $540 \mathrm{~m} \mu$ in time. The optical density of the peak after a prolonged time decreased as follows: 2,3dimethylbutadiene $<$ isoprene $<$ butadiene. The results are shown in Figure 4. A peak was clearly observed at $340 \mathrm{~m} \mu$ in the copolymerization of

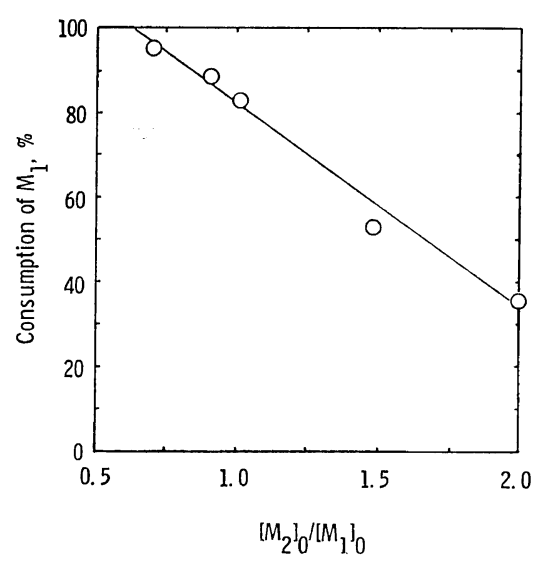

Figure 2. Anionic copolymerization of 2,3-dimethylbutadiene $\left(\mathrm{M}_{1}\right)$ and trans-stilbene $\left(\mathrm{M}_{2}\right)$ by $n$-BuLi in THF. Relationship between monomer composition and polymer yield. $\left[\mathrm{M}_{1}\right]_{0}, 3.96 \mathrm{mmol}$, THF, $15 \mathrm{ml}$, [ $n$-BuLi], $0.058 \mathrm{mmol}$, Temp., $0^{\circ} \mathrm{C}$, Time $62 \mathrm{hr}$.

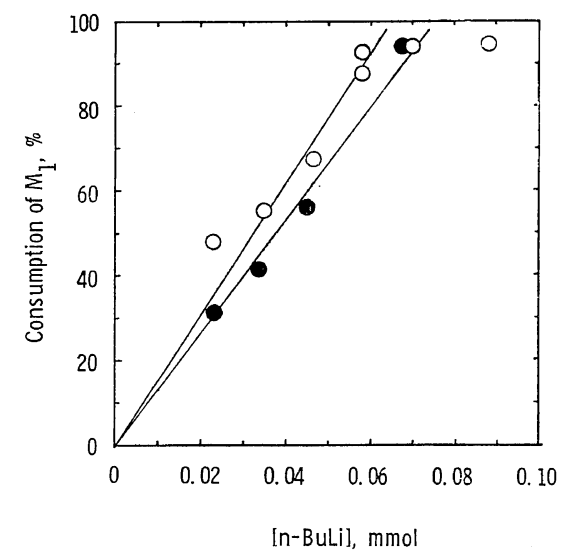

Figure 3. Anionic copolymerizations of transstilbene $\left(\mathrm{M}_{2}\right)$ and dienes $\left(\mathrm{M}_{1}\right)$ by $n$-BuLi in THF. O: [Isp] $0,5.22 \mathrm{mmol},\left[\mathrm{M}_{2}\right]_{0}, 5.02 \mathrm{mmol}$, Time, $40 \mathrm{hr}$. ๑: $[\mathrm{DMB}]_{0}, 4.42 \mathrm{mmol},\left[\mathrm{M}_{2}\right] \mathrm{o}, 4.87 \mathrm{mmol}$, Time, $68 \mathrm{hr}$. THF, $15 \mathrm{ml}$, Temp. $0^{\circ} \mathrm{C}$. 


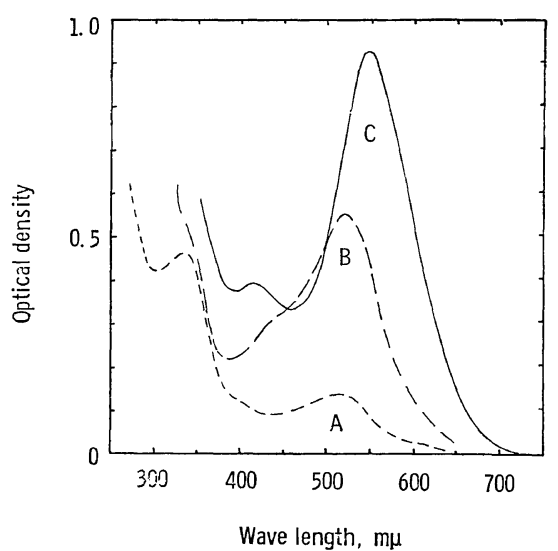

Figure 4. Anionic copolymerizations of dienes $\left(\mathrm{M}_{1}\right)$ and trans-stilbene $\left(\mathrm{M}_{2}\right)$ by $n$-BuLi in THF; electronic spectra of reaction mixtures.

A: $[\mathrm{Bd}]_{0}, 5.42 \mathrm{mmol}, n$-BuLi, $0.040 \mathrm{mmol}$.

B: [Isp] $, 5.33 \mathrm{mmol}, n$-BuLi, $0.045 \mathrm{mmol}$.

C: $[\mathrm{DMB}]_{0}, 5.55 \mathrm{mmol}, n$-BuLi, $0.055 \mathrm{mmol}$.

$\left[\mathrm{M}_{2}\right]_{0}, 5.55 \mathrm{mmol}$, THF, $15 \mathrm{ml}$, Temp., $0^{\circ} \mathrm{C}$, Time, ca. $48 \mathrm{hr}$.

trans-stilbene and butadiene, indicating that trans-stilbene was almost completely consumed and a benzyl type anion remained in the system. The purple solution formed in the copolymerization employing isoprene or 2,3-dimethylbutadiene as a comonomer could not initiate the polymerizations of these monomers or even butadiene.

The microstructures of the dienes in the homopolymers and alternating copolymers were investigated by NMR spectroscopy. The peaks of the proton resonances of the double bonds in the alternating copolymers with isoprene and
Table IV. Microstructure of the dienes in the alternating copolymers and in the homopolymers prepared by $n$-BuLi in THF

\begin{tabular}{|c|c|c|c|c|c|c|}
\hline \multirow[t]{2}{*}{ Diene } & \multicolumn{3}{|c|}{$\begin{array}{c}\text { Alternating } \\
\text { copolymer }(\%)\end{array}$} & \multicolumn{3}{|c|}{$\begin{array}{c}\text { Homopolymer } \\
(\%)\end{array}$} \\
\hline & $1,2-$ & $1,4-$ & $3,4-$ & $1,2-$ & $1,4-$ & $3,4-$ \\
\hline Butadiene & 12 & 88 & - & 81 & 19 & 一 \\
\hline Isoprene & $\sim 0$ & 90 & 10 & 29 & $\sim 0$ & 71 \\
\hline $\begin{array}{l}\text { 2,3-Dimethyl- } \\
\text { butadiene }\end{array}$ & 0 & 100 & 一 & 49 & 51 & - \\
\hline
\end{tabular}

butadiene were found at 4-5 ppm as broad ones, which positions were different from those of the corresponding homopolydienes. The results are summarized in Table IV. In the IR-spectrum, the alternating copolymer of trans-stilbene and isoprene showed a very weak absorption due to a vinyl group at $910 \mathrm{~cm}^{-1}$ and a rather strong absorption due to a terminal methylene group at $890 \mathrm{~cm}^{-1}$. Therefore, it is assumed that this copolymer had little 1,2-structure. In all cases, the 1,4-content was higher in the alternating copolymers than in the corresponding homopolymers. No 1,2-structure was found in the alternating copolymer with 2,3-dimethylbutadiene at all. This may also suggest that the copolymer was alternating.

\section{Polymerization in Benzene}

The copolymerizations of trans-stilbene and the dienes were carried out in benzene at $40^{\circ} \mathrm{C}$. The results are shown in Table V. Although all the dienes were completely consumed, little transstilbene was incorporated into the copolymers except in the copolymerization with 2,3-dimethyl-

Table V. Anionic copolymerizations of trans-stilbene $\left(\mathrm{M}_{2}\right)$ and dienes $\left(\mathrm{M}_{1}\right)$ by $n$-BuLi in benzene

\begin{tabular}{lccccccc}
\hline \multirow{2}{*}{$\mathrm{M}_{1}$} & $\begin{array}{c}\mathrm{M}_{1} \\
(\mathrm{~g})\end{array}$ & $\begin{array}{c}\mathrm{M}_{2} \\
\mathrm{~g})\end{array}$ & $\begin{array}{c}{\left[\mathrm{M}_{1}\right]_{0} /\left[\mathrm{M}_{2}\right]_{0}} \\
(\mathrm{~mol} / \mathrm{mol})\end{array}$ & $\begin{array}{c}\text { Polymer } \\
(\mathrm{g})\end{array}$ & $\begin{array}{c}\text { Recovered } \\
\mathrm{M}_{2}(\mathrm{~g})\end{array}$ & \multicolumn{2}{c}{ Copolymer composition } \\
\hline $\mathrm{Bd}$ & 0.275 & 1.000 & 0.92 & 0.290 & 0.980 & 5.10 & 0.11 \\
$\mathrm{Bd}$ & 0.275 & 1.500 & 0.61 & 0.270 & 1.496 & 5.10 & 0.02 \\
$\mathrm{Bd}$ & 0.275 & 2.000 & 0.46 & 0.290 & 1.985 & 5.10 & 0.08 \\
$\mathrm{Isp}$ & 0.350 & 1.000 & 0.92 & 0.354 & 1.000 & 5.10 & 0.02 \\
Isp & 0.350 & 1.500 & 0.61 & 0.353 & 1.503 & 5.10 & 0.02 \\
Isp & 0.350 & 2.000 & 0.46 & 0.373 & 1.990 & 5.10 & 0.13 \\
DMB & 0.441 & 1.000 & 0.97 & 0.690 & 0.760 & 5.36 & 1.33 \\
DMB & 0.441 & 1.250 & 0.78 & 0.730 & 0.972 & 5.36 & 1.54 \\
DMB & 0.441 & 1.500 & 0.64 & 0.782 & 1.162 & 5.36 & 1.86 \\
\hline
\end{tabular}

a Benzene, $15 \mathrm{ml}, n$-BuLi, 0.07-0.10 mmol, Temp., $40^{\circ} \mathrm{C}$, Time, 5-7 day.

b Bd: Butadiene, Isp: Isoprene, DMB: 2,3-Dimethylbutadiene. 
butadiene. Such a change of color as found in THF did not occur. The copolymer of transstilbene and 2,3-dimethylbutadiene was solid, but the others were viscous liquid.

\section{DISCUSSION}

Since the copolymerizations in THF proceeded alternatingly to give the copolymers, $-\left(\mathrm{M}_{1} \mathrm{M}_{2}\right)_{n^{-}}$, we may regard these copolymerizations as homopolymerizations of $\mathrm{M}_{1} \mathrm{M}_{2}$ or $\mathrm{M}_{2} \mathrm{M}_{1}$ units in a kinetic treatment. The first-order plots taken for the results in Figure 1 are shown in Figure 5. A linear relationship was obtained in the copolymerization of trans-stilbene and butadiene, suggesting that the copolymerization proceeded in first order with respect to the concentration of $\mathrm{M}_{1}$ monomer without termination reaction. In the following propagation reactions

$$
\begin{gathered}
\sim \mathrm{M}_{1}^{-}+\mathrm{M}_{1} \stackrel{k_{11}}{\rightarrow} \rightarrow \cdots \mathrm{M}_{1}^{-} \\
\sim \mathrm{M}_{1}^{-}+\mathrm{M}_{2} \stackrel{k_{12}}{\rightarrow} \sim \sim \mathrm{M}_{2}^{-} \\
\sim \mathrm{M}_{2}^{-}+\mathrm{M}_{1} \stackrel{k_{21}}{\rightarrow} \sim \sim \mathrm{M}_{1}^{-} \\
\sim \mathrm{M}_{2}^{-}+\mathrm{M}_{2} \stackrel{k_{22}}{\longrightarrow} \sim \sim \mathrm{M}_{2}^{-}
\end{gathered}
$$

the rate constant $k_{22}$ must be very small and $k_{12}$ should be much greater than $k_{11}$ in THF, because alternating copolymers were formed. Thus the following relationship can be derived.

$$
k_{21}\left[\mathrm{M}_{2}^{-}\right]\left[\mathrm{M}_{1}\right]=k_{12}\left[\mathrm{M}_{1}^{-}\right]\left[\mathrm{M}_{2}\right]
$$

At $\left[M_{1}\right] \approx\left[M_{2}\right]$, Eq. 5 gives

$$
\frac{\left[\mathrm{M}_{2}^{-}\right]}{\left[\mathrm{M}_{1}^{-}\right]} \approx \frac{k_{12}}{k_{21}}
$$

In the copolymerization with butadiene termination reactions seem to be negligible from Figure 4, which leads to

$$
\left[\mathrm{M}_{1}^{-}\right]+\left[\mathrm{M}_{2}^{-}\right]=[n-\mathrm{BuLi}]
$$

The $\mathrm{M}_{2}^{-}$anion may be more stable than the $\mathrm{M}_{1}^{-}$ anion, since in the copolymerization a deep red color due to the $\mathrm{M}_{2}^{-}$had been clearly observed. So we assumed $\left[\mathrm{M}_{2}^{-}\right] \gg\left[\mathrm{M}_{1}^{-}\right]$, i.e., $k_{12} \gg k_{21}$ from Eq. 6. These lead to ${ }^{2,4}$

$$
-\frac{d\left[\mathrm{M}_{1}\right]}{d t}=k_{21}[n-\mathrm{BuLi}]\left[\mathrm{M}_{1}\right]
$$

If the addition reaction of butadiene $\left(\mathrm{M}_{1}\right)$ to a stilbenyl anion $\left(\mathrm{M}_{2}{ }^{-}\right)$is a rate determining step, the rate constant, $k_{21}$, will be derived from Figure 5 to give $1.0 \mathrm{l} / \mathrm{mol} \cdot \mathrm{sec}$. In the homopolymerization of butadiene, the $k_{11}$ was found to be $0.59 \mathrm{ll}$ $\mathrm{mol} \cdot \mathrm{sec}$ in THF by $n$-BuLi at $0^{\circ} \mathrm{C}^{11}$ Therefore, the above $k_{21}$ seems to be reasonable in magnitude because $k_{12} \gg k_{11} \approx k_{21}$. The overall rates of the copolymerizations of trans-stilbene with dienes

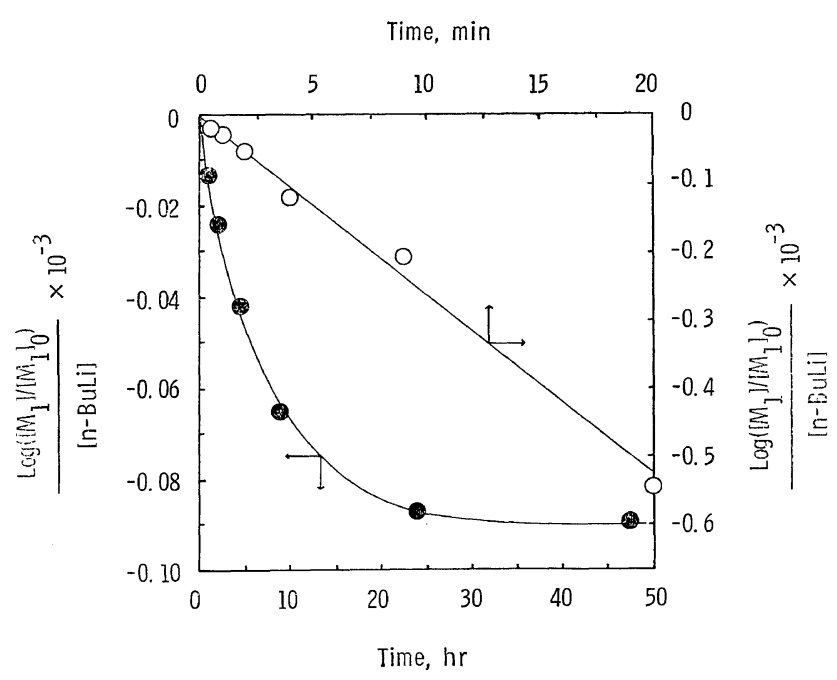

Figure 5. Anionic copolymerizations of trans-stilbene $\left(\mathrm{M}_{2}\right)$ and dienes $\left(\mathrm{M}_{1}\right)$; first-order plots.

: $\mathbf{M}_{1}=$ Butadiene.

: $\mathrm{M}_{1}=2,3$-Dimethylbutadiene.

Reaction conditions are shown in Figure 1. 
were higher than those of the copolymerizations of 1,1-diphenylethylene with the same dienes ${ }^{2,4,5}$ carried out under similar reaction conditions. The difference must be attributed to the rate constant $k_{21}$; i.e., $k_{21}=1.0 \mathrm{l} / \mathrm{mol} \cdot \mathrm{sec}$ in transstilbene-butadiene systems and $k_{21}=0.27 l / \mathrm{mol}$. sec in 1,1-diphenylethylene-butadiene system (at $0^{\circ} \mathrm{C}$ in THF by $n$-BuLi). ${ }^{5} \quad$ The difference may be caused by the fact that the 1,1-diphenylethylenyl anion is more stable owing to the conjugation of two benzene rings and more sterically hindered than the stilbenyl anion.
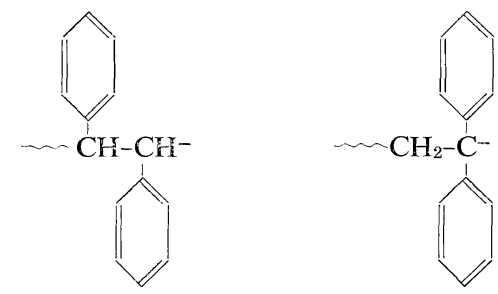

On the other hand, a concave relationship between $\log \left[\mathrm{M}_{1}\right] /\left[\mathrm{M}_{1}\right]_{0}$ and the polymerization time was given in the copolymerization of transstilbene and 2,3-dimethylbutadiene (Figure 5), indicating a decrease in the concentration of active species by any termination reactions along the copolymerization.

In the reaction of trans-stilbene with $n-\mathrm{BuLi}$ in $\mathrm{THF}{ }^{7}$ we found that $\alpha$-proton of trans-stilbene was abstracted by a carbanion to give a stilbene anion, I, which then reacted with trans-stilbene to form a stable carbanion, II.

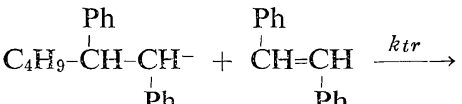

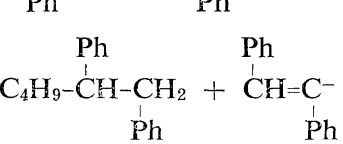

(I)

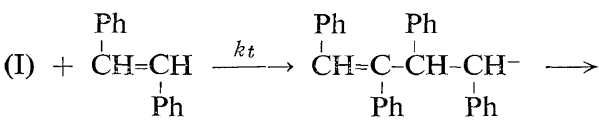

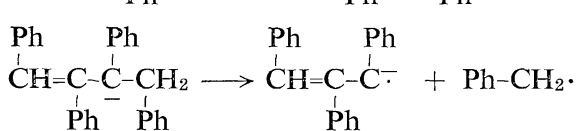

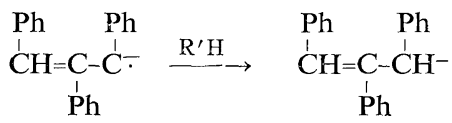

This stable triphenylpropene anion, (II), showed an absorption maximum at $550 \mathrm{~m} \mu$ and could not initiate the polymerizations of the dienes used in the present work. These observations resembled those in the copolymerizations of trans-stilbene with the dienes and suggest that in the copolymerizations a similar reaction takes place between the growing chain end and transstilbene followed by the formation of inactive anion II or some species having similar structures.

$$
\sim \mathrm{M}_{2}^{-}+\mathrm{M}_{2} \stackrel{k t r}{\longrightarrow} \sim \mathrm{M}_{2} \mathrm{H}+\mathbf{I}
$$

Processes 8 and 6 must be the main termination reactions observed in the copolymerizations with isoprene and dimethylbutadiene. In the copolymerization with butadiene the propagation reaction 3 is so much faster than the termination reaction 8 that the latter may take place only after the complete consumption of butadiene. The electronic spectra (Figure 4) may be correlated with the crder of the frequency of the occurrence of the termination, which was 2,3-dimethylbutadiene $>$ isoprene $>$ butadiene.

Owing to the termination reaction the final yield will increase with an increase in the concentration of the initiator as shown in Figure 3 and the molecular weight of the polymer will be constant regardless of the yield at given monomer concentrations if $\left[\mathrm{M}_{1}\right]_{0} \simeq\left[\mathrm{M}_{2}\right]_{0}$, because the molecular weight of the alternating copolymer will be approximately given by Eq. 9 .

$$
D P=\frac{k_{21}\left[\mathrm{M}_{2}^{-}\right]\left[\mathrm{M}_{1}\right]}{k_{t r}\left[\mathrm{M}_{2}^{-}\right]\left[\mathrm{M}_{2}\right]}
$$

Actually, the intrinsic viscosities of the copolymers with isoprene and 2,3-dimethylbutadiene obtained in the copolymerizations in Figure 3 were almost constant.

Because of $k_{22} \simeq 0$ the monomer reactivity ratios, $r_{1}$, could be derived by integrating MayoLewis' equation from the results of the copolymerizations of the dienes $\left(\mathrm{M}_{1}\right)$ and trans-stilbene $\left(\mathrm{M}_{2}\right){ }^{1} \quad$ The values are collected in Table VI. In THF $r_{1}$ values were almost zero in every case, and large differences in the reactivities were found between the copolymerizations in THF and in benzene. Isoprene and butadiene had greater reactivity ratios in benzene than in THF, but 2,3-dimethylbutadiene showed only a small difference. These results are quite in accord with 
those found in the copolymerization of 1,1diphenylethylene and the dienes, ${ }^{4,5}$ where detailed discussions have been done.

Table VI. Anionic copolymerizations of trans-stilbene with dienes by $n$-BuLi (Monomer reactivity ratio, $r_{1}$ )

\begin{tabular}{lcc}
\hline \multicolumn{1}{c}{ Diene } & THF $^{\mathrm{a}}$ & Benzene $^{\mathrm{b}}$ \\
\hline Butadiene & $\sim 0$ & $>50$ \\
Isoprene & $\sim 0$ & $>50$ \\
2,3-Dimethylbutadiene & $\sim 0$ & 8.5
\end{tabular}

a At $0^{\circ} \mathrm{C}$.

b At $40^{\circ} \mathrm{C}$.

The microstructures of the dienes in the polymers prepared in THF seemed to be controlled mainly by the steric factor (Table IV). Although in the homopolymers 1,2- and 3,4-structures were rather favored, in the alternating copolymers the 1,4-structure became more important. This may be caused by

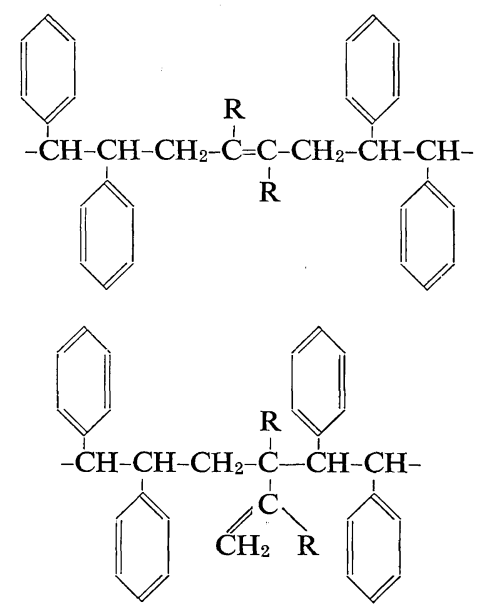

$\mathrm{R}: \mathrm{H}$ or $\mathrm{CH}_{3}$ larger steric hindrances of 1,2- and 3,4-structures in the copolymers than those in the homopolymers. It is obvious that 2,3-dimethylbutadiene has the largest steric hindrance in the dienes. The higher content of the 1,4-structure of the dienes was also found in the copolymerizations of 1,1diphenylethylene and the dienes used here. ${ }^{5}$ These specific microstructures of the dienes taken in the alternating copolymers also suggest the importance of the steric factor in the rate of propagation steps in the copolymerizations.

The difference of the ionic states of the active centers, which is attributed to the common-ion effect of the stilbenyl anion, may also be one of the causes for the higher 1,4-contents in the copolymers, especially in the copolymer with butadiene because of its small steric effect.

\section{REFERENCES}

1. H. Yuki, J. Hotta, Y. Okamoto, and S. Murahashi, Bull. Chem. Soc. Japan, 40, 2659 (1967).

2. H. Yuki, K. Hatada, and T. Inoue, J. Polym. Sci., Part A-1, 6, 3333 (1968).

3. H. Yuki, Y. Okamoto, and K. Sadamoto, Bull. Chem. Soc. Japan, 42, 1754 (1969).

4. H. Yuki and Y. Okamoto, ibid., 42, 1644 (1969).

5. H. Yuki and Y. Okamoto, ibid., 43, 148 (1970).

6. H. Yuki, M. Kato, and Y. Okamoto, ibid., 41, 1940 (1968).

7. Y. Okamoto, M. Kato, and H. Yuki, ibid., 42, 760 (1969).

8. R. L. Shriner and A. Berger, "Organic Syntheses," Coll. Vol. III, John Wiley \& Sons, New York, N.Y., 1955, p. 156.

9. C. F. Allen and A. Bell, ibid., p. 312.

10. K. Ziegler and H. Colonius, Ann., 479, 135 (1930).

11. M. Morton, E. E. Bostick, R. A. Livigni, and L. J. Fetters, J. Polym. Sci., Part A, 1, 1735 (1963). 